\title{
Inhalt
}

Monika E. Müller und Markus Friedrich

Einführung - 1

\section{Der Sammler}

Helmut Zedelmaier

Zacharias Konrad von Uffenbach

Fünf Schlaglichter auf einen gelehrten Sammler — 11

Julia A. Schmidt-Funke

Der Sammler und die Seinigen

Die Frankfurter Brüder von Uffenbach im Kontext städtischer

Sammlungspraxis -69

Frank Fürbeth

Privater Buchbesitz in Frankfurt vom Spätmittelalter bis zu Zacharias Konrad von Uffenbach -93

Axel E. Walter

Zacharias Konrad von Uffenbach und das Bibliothekswesen seiner Zeit

Kritische Bestandsaufnahme und inhärenter Gegenentwurf in seinen

Merkwürdigen Reisen durch Niedersachsen, Holland und

Engelland -125

Heike Düselder

„Perlen aus dem Mist heraus geklaubt“

Wissens- und Sammlungsbestände einer frühneuzeitlichen Hansestadt im Blick eines reisenden Gelehrten — 165

\section{Die Sammlung}

Friederike Berger

Die griechischen Handschriften des Zacharias Konrad von Uffenbach — 185 
Katrin Sturm

Handschriften aus dem Besitz des Zacharias Konrad von Uffenbach in der Universitätsbibliothek Leipzig

Mit einem Anhang der im Bestand identifizierbaren

Handschriften — 207

Monika E. Müller

„Vortrefflich nützliche Bilderbücher [...]“?

Die Codices picturati des Zacharias Konrad von Uffenbach — 231

Markus Friedrich

Von Zürich nach Frankfurt nach Hamburg

Die Reise der Quellenexzerpte Johann Heinrich Otts (1617-1682)

durch Mitteleuropa und Konrad Zacharias Uffenbachs Rolle für die

Täufergeschichtsschreibung des 18. Jahrhunderts - 265

\section{Das Sammeln}

Marcus Stiebing

Die Nutzung einer Gelehrtensammlung

Überlegungen zur Bibliotheca Uffenbachiana Universalis — 293

Ines Peper

„Nach altem Gesetz sollen die Tore der Musen offen stehen“

Der Briefwechsel Zacharias Konrads von Uffenbach mit dem Melker

Benediktiner Bernhard Pez — 319

Mona Garloff

Zacharias Konrad von Uffenbach und der Buchhandel - 335

Sebastian Pranghofer

Anatomisches Wissen im gelehrten Urteil

Zacharias Konrad von Uffenbach und die ästhetisch-moralischen

Werte der experimentellen Wissenschaften um $1700-361$

Jacob Schilling

Uffenbachs Beziehungen zu den Medizinern der Academia Naturae

Curiosorum -385

Register -413 